\title{
Experiential Realizations of Pedagogic Discourse in an Indonesian EFL Classroom
}

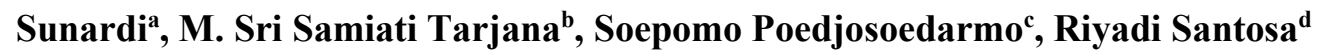 \\ b,c,d Department of Linguistics, Doctoral Program, Sebelas Maret University Surakarta, Indonesia \\ ${ }^{1}$ English Department, Dian Nuswantoro University Semarang, Indonesia \\ Corresponding e-mail: soenklaten@gmail.com
}

\begin{abstract}
This paper aims at finding the schematic structure of a pedagogic discourse in an Indonesian EFL classroom and describing the process types used in the discourse as the experiential meaning realizations. The data of this study was a video-taped EFL classroom taught by a non-native English lecturer in a university in Semarang. The data were analyzed by referring to the analytical framework of Transitivity System under Systemic Functional Linguistics. The findings show that the schematic structure of the pedagogic discourse was carried out in three general stages: orientation, discussion, and closure stages. Each stage was operated through several potential pedagogic steps. In terms of the predominant process type selected in each stage, the orientation stage was dominated by relational and material processes. The discussion stage was dominated by relational process; and the closure stage was dominated by material process.
\end{abstract}

Keywords: experiential meaning, transitivity analysis, EFL pedagogic discourse, schematic structure

\section{INTRODUCTION}

Pedagogic discourse has now become interesting object for many studies in the field of linguistics and education. Pedagogic discourse analysis shows how classroom text is constructed and captures all social practices involved in educational activities. Bernstein (as cited in Christie (2000: 313) and Rose (2014: 1) proposes that a pedagogic discourse has two elements: a regulative discourse and an instructional discourse. A regulative discourse refers to the pedagogic goals and the organization of the classroom activities to accomplish the pedagogic goals, while an instructional discourse refers to the knowledge and skills taught and learned in the pedagogic activity. Because the unfolding of the pedagogic discourse is operated by using sets of language choices, Christie (2000: 315) calls the two elements of pedagogic discourse as a regulative register and an instructional register.
Some pedagogic discourse studies have been conducted by focusing on the generic stages and experiential realizations in SFL which include Christie's (1991) study in writing planning genres in Australian primary schools; Young's (1994) study in Canadian university lectures on engineering, sociology, and economics; and Sinar's (2002) study in Malaysian university lectures on language teaching and linguistics. Christie (1991) found that the writing planning genre had three elements: Task Orientation, Task Specification, Task, which can be represented as $\mathrm{TO}^{\wedge} \mathrm{TS}^{\wedge} \mathrm{T}$ where $\wedge$ indicates sequence. In addition, Christie also found that the pedagogic activities were operated in regulative and instructional registers. Different from Christie's study which used Martin's theory of genre, Young (1994) analyzed university lectures using Gregory's theory of planal and stratal assignment in communication linguistics (1985). According to Young, a lecture discourse consisted of 
seven phases, which occurred dynamically and discontinuously. The seven phases together with their experiential realizations were discourse structuring phase in material process, content phase in relational process, conclusion phase in mental process, evaluation phase in relational process, example phase in relation process, interaction phase, and background phase. Sinar (2002), using the same theoretical framework as Young's study, analyzed phases and experiential realizations of lecture discourses in Malaysian universities. She found that a lecture discourse was dominated by substantiation, conclusion, and evaluation phases. In terms of experiential realization, a lecture discourse was predominantly realized in relational process.

Those experiential realization studies of pedagogic discourse took place mostly in the classrooms of English as a second language (ESL) in the contexts other than Indonesian context. Thus, a study under SFL analytical framework on the experiential realizations of pedagogic discourse in Indonesian EFL classroom is needed. This paper presents how the pedagogic activities in an EFL classroom in Indonesian context unfold in achieving the pedagogic goals and what kind of experiential realizations are construed in those pedagogic activities

\section{METHODS}

This study is designed in descriptive qualitative research in the form of discourse analysis. The study is qualitative in nature intended to understand and interpret social interaction between lecturers and students in pedagogic setting. The study is also descriptive because it attempts to describe systematically linguistic facts found in pedagogic activity. This study was conducted by analyzing EFL pedagogic discourse by employing SFL analytical framework, particularly the experiential meaning realization.

The data was an EFL classroom discourse taken from an English department in a university located in Semarang, Indonesia. The department has undergone accreditation assessment by the National Board of Higher Education Accreditation, Republic of Indonesia, and it was rated as an excellent English department. The discourse was produced by a domestic English lecturer and students involved in the EFL classroom under study. So, both the lecturer and the students were non-native speakers of English. The lecturer in this EFL classroom was selected purposively by considering his qualification background as an EFL lecturer and the possibility of his lecture to reveal the phenomena being studied. This selection was in accordance with the meaning of purposive sampling as stated by Denzin and Lincoln (1994: 202) who defined purposive sampling as the process of selecting individuals where the processes being studied are most likely to occur. His qualification background included his $\mathrm{PhD}$ degree in applied linguistics, some completed trainings in EFL teaching, teaching experience for 22 years, and academic title as an Associate Professor in linguistics. Based on his background, he could be described as a well-educated, well-trained, and well-qualified lecturer.

The name of the subject was English Syntax. When the classroom was video-taped and observed, it was discussing the theory and analysis of English phrases. The data was analyzed using Martin's (1992) theory on genre to know the schematic structure, and Halliday \& Matthiessen's theory on Transitivity system to know the experiential meaning realizations of the EFL pedagogic discourse.

In data analysis, the lecture discourse was identified its schematic structure by segmenting the pedagogic stages and steps carried out throughout the lecture to achieve the communicative purpose of the lecture. Once the existing pedagogic stages and steps were identified, the clause boundaries of the utterances were segmented. To know the experiential realizations, the experiential components of each clause were identified into process type and related participants and circumstances.

Once the lexicogrammatical analysis was accomplished, an interpretation of the experiential realizations in the unfolding of EFL pedagogic discourse in Indonesian context was conducted.

\section{FINDING AND DISCUSSION}

\subsection{Schematic Structure}

The EFL pedagogic discourse under study consisted of lecturer-students exchanges in learning English syntax learning materials. The topics being discussed were phrase types in English and their syntactic analyses in the form of tree diagram from functional and categorical points of view. The communicative goal of this lecture was to enable students to understand English phrase types and analyze the phrases from functional and categorical points of view. To achieve 
the goal, the lecturer sequenced the pedagogic activities in such a way that made three major stages: orientation, discussion, and closure. Each stage was carried out in some smaller steps. Schematically, the structure of this EFL pedagogic discourse could be displayed as follows, where the sequence was indicated by $\wedge$, the recursion was indicated by $\pi$, and the domain of recursion was indicated by [ ] (Christie, 2002: 35).

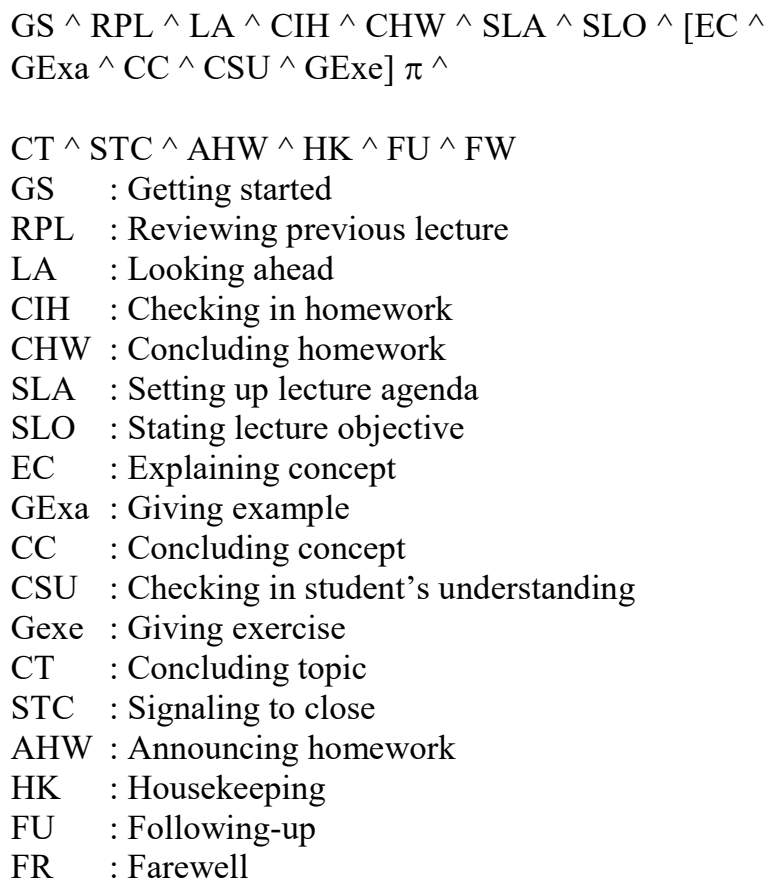

Seen from the macrostructure, the EFL pedagogic discourse was initiated with an orientation stage to prepare students' mental readiness to learn the new knowledge and skills, and then followed with discussion stage to deliver and study the knowledge and skills, and finally ended with closure stage to ensure students' completion of the tasks and achievement of the lecture goals.

The step-by-step organization of the lecture was not reflected only by the sequence of orientationdiscussion-closure structure. Inside each stage there were also some potential steps which were sequentially carried out for the completion of the stage. Orientation stage was carried out sequentially through some steps: getting started, reviewing previous lecture, looking ahead, checking in homework, concluding homework, setting up lecture agenda, and stating lecture objective. Next, discussion stage, which constituted the main activity of the lecture, was carried out through explaining concept, giving example, concluding concept, checking in student's understanding, giving exercise, and concluding topic. Discussion stage moved in a recursive phase (indicated with the brackets [ ] and the symbol $\pi$ ), because in the course of this main activity the lecture discussed the types of English phrases: noun, adjective, adverb, verb, and prepositional phrases. The domain of recursion included explaining concept, giving example, concluding concept, checking in student's understanding, and giving exercise. This recursive phase occurred in the discussion of every phrase type. Beyond the recursive phases, the discussion stage ended with the step of concluding topic in which the lecturer summarized and concluded the lesson topic. In addition, the closure stage was sequentially carried out through the steps of signaling to close, announcing homework, housekeeping, following-up, and farewell.

The emerging stages and steps and their communicative purposes in the EFL pedagogic discourse can be summarized in Table 1 .

\subsection{The students}

The realizational patterns of experiential meaning in the EFL pedagogic discourse under study were determined by applying Transitivity analysis in which every clause was segmented into its experiential components of process and related participants and circumstance. In Transitivity system, the central component is process, which tells what is going on in a clause (Gerot and Wignell, 1995: 54). So, the experiential realizations of this EFL pedagogic discourse were determined and interpreted based on the use of processes in the overall pedagogic stages and steps. Table 2 presents the types of process construed in the overall clauses used by lecturer and students in the EFL pedagogic discourse under study.

Table 2 shows that the EFL pedagogic discourse uses all six types of process in Transitivity system with different distribution. Relational processes of attribution and identification are most frequently used in the discourse occurring in 414 clauses or nearly 59\% of all clauses produced in the discourse. The second most frequently used process is the material process with 152 clauses or $21.5 \%$, followed by verbal, mental, 
existential, and behavioral processes. The dominant occurrence of relational process over the other processes indicates.

That pedagogic discourse is characterized by the frequent use of relational process. This is in line with Gerot and Wignell (1995: 69) who state that relational processes play a key role in education in subjects such as science to create technicality and a way of classifying the world.

The EFL pedagogic discourse under study occurs in an academic setting, that is, it is an interaction between lecturer and students in pursuing knowledge and skills. As a person responsible for transferring knowledge to students in pedagogic activity, the lecturer explains the concepts learned by using relational processes, either by giving attributes to the concepts or by giving identities to the concepts. In this discourse, most of the relational processes are realized in relational process of identification with 291 clauses or $70 \%$, while relational processes of attribution are used in 123 clauses or $30 \%$.

In an attributive relational clause, an entity has some class ascribed or attributed to it (Halliday and Matthiessen, 2014: 267). This type of clause construes the relationship between two things: the entity (Carrier) and the specification/quality of the entity (Attribute). The two attributive relational clauses above are used by the lecturer to explain students the possible types of phrase in English language through what Halliday and Matthiessen (2014: 262) call as a class-membership relationship. In The possibilities of the phrase that we can make or that we can produce will be one of the five phrases, the entity which becomes the class is the possible phrases, while the member of the class is one type of phrase. The next clause also shows attributive relationship between It as the class and a noun phrase, adjective phrase, adverb phrase, verb phrase, or prepositional phrase as the member. The use of such attribution or specification clause may give clearer explanation on a concept learned in pedagogic activity.

In an identifying relational clause, something has an identity assigned to it, that is, one entity is being used to identify another (Halliday and Matthiessen, 2014: 267). The two identifying relational clauses above are used by the lecturer to define the concept of noun phrase. In A noun phrase is a phrase with a noun as its most important or most dominant constituent of the phrase, the entity being defined (Token) is a noun phrase and the identity to assign (Value) is a phrase with a noun as its most important or most dominant constituent of the phrase. The second clause also gives definition about a noun phrase by identifying the head word of a phrase, making What makes the phrase is a noun phrase as Token and the existence of a noun as the most important word or the most important constituent of the phrase as Value. The more uses of attributive and identifying relational processes in the pedagogic discourse may help students' understanding on the concepts learned. Identifying relational clause differs from attributive relational clause in its capability for reversion, that is, identifying relational clause is reversible in order and the semantic relationship still holds (Gerot \& Wignell, 1995: 69).

Another experiential realization finding in this EFL pedagogic discourse is the more frequent use of material clauses after relational clauses. Material process expresses that some entity physically does something, which may be done to some other entity. The use of material clauses, particularly in discussion stage, reflects that together with relational process, material process constitutes the main going-on construed in the discussion stage. Material process and relational process are construed in 566 or $90 \%$ clauses used in the discourse, showing the significant construal of processes of doing and being in the whole discourse. The use of material clauses in the discourse shows that the pedagogic activities are centrally focused on lecturer's and students' actions in relation to the topics of the lecture. Some physical doing-verbs expressing students' activities in the lecture include start, study, combine, develop, give, describe, read.

Material clauses construe some processes of doing in pedagogic activities, such as study, develop, and give, acted by we, I (Participant: Actor) towards extended participants (Goal): parts of speech in English, the words studied in the previous meeting, you (students), and some examples of noun phrase.

Other process types beside relational and material processes are also construed. Verbal, mental, behavioral, and existential clauses used in the discourse reflect lecturers' and students' activities in verbal, mental, behavioral, and existential processes with respect to the lecture contents, i.e. phrases in English language. Some verbs realizing these 
processes include know, understand, tell, call, distinguish, exist, is.

Various processes are also realized in different steps in each stage. Material process and identifying relational process dominate the experiential realizations in orientation stage. This happens because the pedagogic exchanges in orientation stage are centrally focused to checking in students' homework, concluding the learning points from homework, and setting lecture agenda. Material clauses are employed to construe lecturer's and students' activities dealing with homework and the activities to do in the next stage, while identifying relational clauses are used by lecturer to clarify the lecture topics through definition.

Relational processes dominate the experiential realizations in the overall steps in discussion stage. The type of relational process more frequently used is that of identification, followed by relational process of attribution, material process, mental process, verbal process, and existential process. The least frequently used process is behavioral process. The central focus of discussion stage is lecturer's presentation about the lecture contents and students' understanding on the concepts learned in the lecture. The focus is realized in lexicogrammar through relating two entities about the lecture contents through attribution and identification. Concepts of English phrases are made easily understood by the students by giving specification or attribute and defined identity.

From 24 clauses used in closure stage, material process dominates the experiential realizations with 8 clauses or $33.3 \%$, followed by identifying relational process and verbal process with 5 clauses or $20.8 \%$ each, and then followed by mental process and existential process with 4 clauses or $16.6 \%$ and 2 clauses or $8.3 \%$ respectively. The domination of material process over the other processes in the overall stages in closure stage reveals the significant construal of process of doing in this stage. The focus of closure stage is students' completion of the tasks and achievement of the learning outcomes. Most of the material processes in closure stage are employed in the step of following-up, showing lecturer's expectation on what students need to do to increase their understanding on the concepts learned in the pedagogic discourse.

Table 1 The schematic structure of the EFL pedagogic discourse

\begin{tabular}{|c|c|c|}
\hline Stage & Step & Communicative Purpose \\
\hline \multirow[t]{8}{*}{ Orientation } & & $\begin{array}{l}\text { To prepare student's mental readiness to learn new } \\
\text { knowledge and skills }\end{array}$ \\
\hline & Getting started & To indicate that the lecture has officially begun \\
\hline & Reviewing previous lecture & To activate student's prior knowledge \\
\hline & Looking ahead & To inform student of what to expect in the future \\
\hline & Checking in homework & To ensure student's completion of the homework \\
\hline & Concluding homework & $\begin{array}{c}\text { To conclude the learning points from the } \\
\text { homework }\end{array}$ \\
\hline & Setting up lecture agenda & To outline the agenda of the lecture \\
\hline & Stating lecture objective & To state the expected learning outcomes \\
\hline \multirow[t]{7}{*}{ Discussion } & & $\begin{array}{c}\text { To deliver and learn the new knowledge and skills } \\
\text { of the lecture }\end{array}$ \\
\hline & Explaining concept & To present new concepts and skills to learn \\
\hline & Giving example & To give real examples on the concepts learned \\
\hline & Concluding concept & To conclude the main points of the concept learned \\
\hline & Checking in student's understanding & $\begin{array}{c}\text { To examine student's comprehension before } \\
\text { exercise }\end{array}$ \\
\hline & Giving exercise & $\begin{array}{l}\text { To check student's comprehension through } \\
\text { problems }\end{array}$ \\
\hline & Concluding topic & $\begin{array}{l}\text { To conclude all concepts and skills learned in the } \\
\text { lecture }\end{array}$ \\
\hline \multirow[t]{2}{*}{ Closure } & & $\begin{array}{l}\text { To ensure student's completion of the tasks and } \\
\text { achievement of the learning outcomes }\end{array}$ \\
\hline & Signaling to close & To indicate the lecture will end \\
\hline
\end{tabular}




\begin{tabular}{|c|c|c|}
\hline Stage & Step & Communicative Purpose \\
\hline & Announcing homework & $\begin{array}{l}\text { To announce the assignment to complete by } \\
\text { students at home }\end{array}$ \\
\hline & House keeping & To remind student's attendance \\
\hline & Following-up & To suggest on what to read in the next lecture \\
\hline & Farewell & To formally signal the end of the lecture \\
\hline
\end{tabular}

Table 2 Processes used in the overall stages

\begin{tabular}{|c|c|c|c|c|c|c|c|c|c|}
\hline \multirow[b]{2}{*}{$\begin{array}{c}\text { Stag } \\
\mathrm{e}\end{array}$} & \multirow[b]{2}{*}{$\begin{array}{c}\text { Materi } \\
\text { al }\end{array}$} & \multicolumn{3}{|c|}{ Mental } & \multirow[b]{2}{*}{$\begin{array}{l}\text { Verb } \\
\text { al }\end{array}$} & \multirow[b]{2}{*}{$\begin{array}{l}\text { Behavio } \\
\text { ral }\end{array}$} & \multicolumn{2}{|c|}{ Relational } & \multirow[b]{2}{*}{$\begin{array}{c}\text { Existent } \\
\text { ial }\end{array}$} \\
\hline & & $\begin{array}{l}\text { Cogniti } \\
\text { ve }\end{array}$ & $\begin{array}{l}\text { Affecti } \\
\text { ve }\end{array}$ & $\begin{array}{c}\text { Percepti } \\
\text { ve }\end{array}$ & & & $\begin{array}{c}\text { Attributi } \\
\text { ve }\end{array}$ & $\begin{array}{c}\text { Identifyi } \\
\text { ng }\end{array}$ & \\
\hline Orientation & 19 & 7 & 1 & 0 & 1 & 0 & 0 & 18 & 0 \\
\hline Discussion & 125 & 33 & 1 & 5 & 54 & 6 & 123 & 268 & 21 \\
\hline Closure & 8 & 2 & 2 & 0 & 5 & 0 & 0 & 5 & 2 \\
\hline $\begin{array}{c}\text { Total } \\
\text { processes }\end{array}$ & 152 & 42 & 4 & 5 & 60 & 6 & 123 & 291 & 23 \\
\hline Total clauses & & & & & 706 & & & & \\
\hline Percentage & 21.5 & 5.9 & 0.6 & 0.7 & 8.5 & 0.8 & 17.4 & 41.2 & 3.3 \\
\hline
\end{tabular}

\section{CONCLUSIONS}

As a staged and goal-oriented social process, the EFL pedagogic discourse under study is unfolded in three general pedagogic stages: orientation, discussion, and closure stages. Each stage is operated through some smaller steps. Orientation stage is operated through the steps of getting started, reviewing previous lecture, looking ahead, checking in homework, concluding homework, setting up lecture agenda, and stating lecture objective. Discussion stage is operated through the steps of explaining concept, giving example, concluding concept, checking in student's understanding, giving exercise, and concluding topic. Closure stage is operated through the steps of signaling to close, announcing homework, housekeeping, following-up, and farewell. In terms of processes used as the experiential realizations of the discourse, orientation stage is dominated by relational and material processes; discussion stage is dominated by relational process; and closure stage is dominated by material process.

Because pedagogic discourse is characterized by frequent use of relational process, it is suggested to teachers to understand more about relational process with its sub-types of attribution and identification. The proper use of relational process together with material process in pedagogic discourse may encourage student's active participation in the pedagogic activity and may increase student's understanding of the lecture contents.

\section{REFERENCES}

Christie, F. (1991). Pedagogical and content registers in a writing lesson. Linguistics and Education, 3, 203224 .

Christie, F. (2000). Pedagogic discourse in the postcompulsory years: pedagogic subject positioning. Linguistics and Education 11(4), 313-331.

Christie, F. (2002). Classroom discourse analysis: A functional perspective. London: Continuum. 
Denzin, N. K., Lincoln, Y. S. (1994). Handbook of qualitative research. Thousand Oaks: Sage.

Gerot, L. \& Wignell, P. (1995). Making sense of functional grammar. Sydney: Gerd Stabler.

Martin, J. R. (1992). English text: System and structure. Philadelphia: Benjamins.

Martin, J. R., Matthiessen, C. M. I. M., Painter, C. (2010). Deploying functional grammar. Beijing: The Commercial Press.

Rose, D. (2014). Analysing pedagogic discourse: an approach from genre to register. Functional Linguistics 2, 2-32. Retrieved from http://www.functionallinguistics.com/2/1/11.

Sinar, T. S. 2002. Phasal and Experiential Realizations in Lecture Discourse: A Systemic Functional Perspectives. Doctoral Dissertation, University of Malaya Malaysia. Retrieved from www.diglib.um.edu.my/umtheses/.

Young, L. 1994. University lectures: Macro-structures and micro-features. In Flowerdew, J. (Ed.). Academic listening: Research perspectives (pp. 159-176). London: Cambridge University Press. 